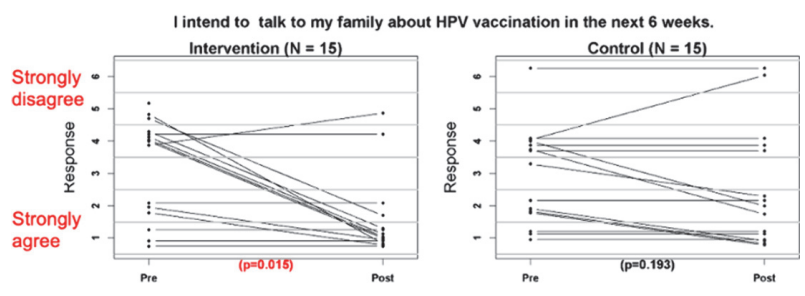

Abstract EPV232/\#585 Figure 1

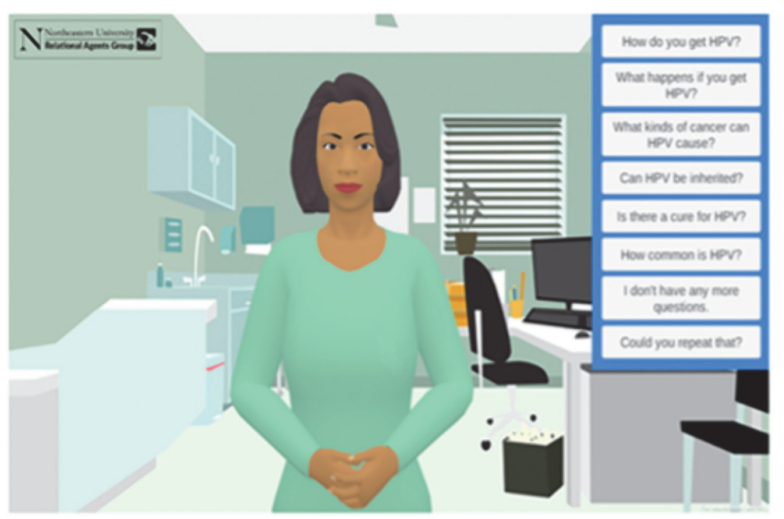

Abstract EPV232/\#585 Image 1 Screenshot of RA

This pilot study assesses the acceptability of RA-based intervention and its impact on survivor intention to discuss vaccination.

Methods Thirty patients with cervical cancer or dysplasia were recruited between 11/2020 and 2/2021 at Karmanos Cancer Institute. The control group $(n=15)$ received an educational brochure and the intervention group $(n=15)$ engaged in a virtual discussion with the RA. Participants completed surveys assessing attitudes toward the RA, intention to discuss HPV vaccination with family, HPV knowledge, and attitudes toward HPV vaccination before and after reviewing the RA.

Results When measured by responses of satisfied or very satisfied; $86 \%$ thought the RA was easy to talk to and liked talking with the RA, while $80 \%$ found it trustworthy. Participants receiving the RA intervention demonstrated stronger intention to discuss HPV vaccination with family compared to control (figure 1).

Conclusions These results demonstrate that simulated healthcare providers such as RA's are an acceptable educational tool that could be adapted for diverse populations in both high and low resource settings. Additionally, the RA may increase intention to discuss HPV vaccination, indicating potential to increase advocacy for HPV vaccination by cervical cancer survivors globally.

\section{EPV233/\#102 COMPARISON OF LOCALIZED AND INTRAVENOUS ANALGESIA TREATMENT IN WOMEN UNDERGOING L.L.E.T.Z UNDER GENERAL ANESTHESIA}

${ }^{1} \mathrm{G}$ Haran*, ${ }^{2} \mid$ Fainberg, ${ }^{2} \mathrm{D}$ Millatiner, ${ }^{2} Y$ Vinnikov, ${ }^{2} \mathrm{~S}$ Bochobza. ${ }^{1} \mathrm{Tel}$ Aviv University, Medicine Faculty, Tel Aviv, Israel; ${ }^{2}$ Maayanei HaYeshua Medical Center, Gyn-Onc Unit, Benei Brak, Israel

10.1136/ijgc-2021-IGCS.304
Objectives Conization is currently performed under general anesthesia with IV analgesia or without anastesia, with local analgesia injected to the cervix. Woelber \& co compared the incidence and intensity of pain after conization under general/ local anesthesia and found no significant differences. No study has compared the effect of analgesia administered via IV or local routh. This study aim to determin pain\&bleeding rate when undergoing conization, depending on routh of analgesia. Methods A prospective blind-control study comparing 30 women undergoing cervical conization under general anastesia in our hospital between 2019-2020. 15 women (A) were administered intravenous analgesia, and 15 women (B) were administered local analgesia injection to cervix. Chi-Square test was used to find the group diffrences.

Results From 30 patients recruited, 14 left in group A and 15 in group B. No demographics differences were found. Extra analgesia in the 24 hours post-Op was found in $14.3 \%(\mathrm{~A})$ and $28.6 \%$ (B) (p-value <0.05). Most reported no pain in the first hour after conization, with the pick of pain appearing 4-8 (A) and 8-12 (B) hours after conization. Amount of intra-op bleeding was $<100 \mathrm{ml}$ in $21.4 \%$ (A) and $80 \%(\mathrm{~B})$ (pvalue $=0.003$ ). Post-conization bleeding was $<100 \mathrm{ml}$ in $42.9 \%$ (A) and $71.4 \%$ (B) with no statistical significancy. One patient from group $B$ needed hemostasis intervention 3 weeks after conization.

Conclusions Conization of the cervix under local analgesia is as effective in pain prevention as general analgetica and reduce the amount of bleeding during and possibly after the operation. More resurch is needed to conclude the preferred routh of analgesia.

\section{EPV234/\#208 OUTCOME AFTER LOOP ELECTROSURGICAL EXCISION PROCEDURE FOR CERVICAL HIGH- GRADE SQUAMOUS INTRAEPITHELIAL LESION}

ST Kwok*, SF Ngu, KLK Chan, KY Tse, MYM Chu, SKL Lau, PNH Sheung. Queen Mary hospital, Oandg, Hong Kong SAR, Hong Kong PRC

\subsection{6/ijgc-2021-IGCS.305}

Objectives The dilemma in treating cervical high-grade squamous intraepithelial lesion (HSIL) is how to achieve complete excision of HSIL to minimize the risk of cervical cancer while sparing the anatomy of the cervix and its ability to function during pregnancy. The optimal management for positive margins after excisional treatment is still controversial. This study was conducted to determine the clinical and histologic predictors of residual/recurrent cervical HSIL and assess the outcome of women with positive margin for HSIL.

Methods This was a retrospective cohort study included 386 women who had excisional treatment for HSIL during 1st January 2012 to 31st December 2015 in Queen Mary Hospital (QMH).

Results 212 (54.9\%) had negative margins and 155 (40.2\%) had positive margins. The rate of residual/recurrent HSIL was $14.6 \%$ in positive margins and $3.7 \%$ in negative margins. Significantly more women with positive margins had residual/ recurrent HSIL compared to negative margins $(74.1 \%$ vs $25.9 \%, p=0.001)$. This was significantly associated with age $\geq 40$ years, positive margins and endocervical glandular involvement. Positive margins had significantly associated with higher rate of subsequent abnormal cervical smear $(48.2 \%$ vs $28.9 \%, \mathrm{p}<0.001)$, requiring further colposcopy $(32.1 \%$ vs 
$14.4 \%, \mathrm{p}<0.001)$ and further treatment for SIL $(7.5 \%$ vs $4.8 \%, \mathrm{p}<0.001)$ compared to negative margin.

Conclusions Most women (85\%) with positive margin went without residual/recurrent HSIL, of which the option of close surveillance with cytology is reasonable. Repeat excision may be considered in selected women with positive margin, endocervical glandular involvement and those who are older or unable to comply with follow-up.

\section{EPV235/\#261 OUTCOMES FOLLOWING REFERRAL TO COLPOSCOPY WITH A HIGH-GRADE SMEAR IN WOMEN AGED 50 YEARS AND ABOVE}

R Shah*, E Leung, D Mukhopadhyay. Queen's Hospital, Barking, Havering and Redbridge University NHS Trust, Gynaecologic Oncology, London, UK

\subsection{6/ijgc-2021-IGCS.306}

Objectives Interpretation of smears is a challenge in older women owing to atrophic changes. Colposcopy can be difficult and views are often unsatisfactory. Approximately $60 \%$ of cervical cancers occur in women aged 45 plus; evidence shows a second peak of high-risk HPV in postmenopausal women. This study aims to establish whether high-grade smear cytology correlates with colposcopic and histological findings in women aged 50 or above and review the employed subsequent management.

Methods A retrospective study was conducted of all women aged 50 years and above, referred to Queen's Hospital colposcopy unit due to high-grade smear between 2016-2019. An electronic data search was undertaken to establish colposcopy findings, histology of biopsy, LLETZ, or further surgical intervention plus results following tests of cure. Data was analysed using Microsoft Excel.

Results Smear cytology for the 99 women referred demonstrated 1 suspicious of glandular neoplasia, 50 of severe, and 48 of moderate dyskaryosis. 11 patients were excluded due to incomplete data. Colposcopic views were unclear for $27(31 \%)$ patients. 82(93\%) patients underwent LLETZ. 3 squamous cell carcinomas and 1 adenocarcinoma were detected. High-grade histology was seen in 54 samples (23\% CINII and $38 \%$ CINIII), low-grade histology in $11(13 \%$ CINI), $11 \%$ had no abnormality and $10 \%$ displayed other benign changes. 10 patients went on to have a total hysterectomy and bilateral salpingo-oophorectomy.

Conclusions A 5\% incidence of cancer and 61\% high-grade histology was found in this cohort, with 11\% undergoing radical surgical intervention. This demonstrates the need for robust cervical screening programmes, particularly in conflicting smear and colposcopy findings.

\section{EPV236/\#321 CAN MIDWIVES EFFICIENTLY PERFORM CERVICAL CANCER SCREENING?}

${ }^{1} \mathrm{~K}$ Ben Hamida*, 'M Ghalleb, 'A Triki, 'I Jebir, ${ }^{2} \mathrm{D}$ Halleb, ${ }^{1} \mathrm{R}$ Makhlouf, ${ }^{1} \mathrm{H}$ Touinsi. ${ }^{1}$ Mohamed Taher Al-Maamouri Hospital, General Surgery Department, Nabeul, Tunisia; ${ }^{2}$ Family Planning Center of Nabeul, Women and Children Health Department, Nabeul, Tunisia

10.1136/ijgc-2021-IGCS.307
Objectives In Tunisia, cervical cancer is the third cancer in women affecting 250 to 300 women/year. Unfortunately, patients are still diagnosed in an advanced stage. Midwives hold a capital role in cervical cancer screening since they are the first line of our national screening program. We aim through this work to prove their efficiency in reducing the incidence of invasive cervical cancer.

Methods Data were collected from registries of the Family Planning Center of Nabeul, Tunisia, from January 2015 to December 2019.

Results From January 2015 to December 2019, 3745 PAP smears were performed (the mean number was 740 PAP smears per year). For 2801 women $(73.6 \%)$, it was the first time they had a PAP smear, and for 944 women (26.4\%), it was the second time. Time to response was 5.5 weeks (range 3 to 8.6). Normal cytology represented 74.74\%. Inadequate PAP smear represented only $2.1 \%$. The inflammatory cytology was rated $20.5 \%$. Atypical squamous cells of undetermined significance (ASC-US) represented $0.55 \%$ of all specimens. Low-grade squamous intraepithelial lesions (LSIL) were $0.94 \%$. High-grade squamous intraepithelial lesions (HSIL) represented $0.90 \%$.

Conclusions These data showed that midwives could correctly perform PAP smear, thereby confirming their substantial role in cervical cancer screening.

\section{EPV237/\#541 TWO-YEAR EFFECTIVENESS OF TOPICAL IMIQUIMOD TREATMENT OF HIGH-GRADE CERVICAL INTRAEPITHELIAL NEOPLASIA (TOPIC-3)}

${ }^{1} \mathrm{~N}$ Hendriks*, ${ }^{2} \mathrm{M}$ Koeneman, ${ }^{1} \mathrm{~B}$ Slangen, ${ }^{3} \mathrm{~A}$-J Krüse. 'Maastricht University Medical Center, Gynaecology and Obstetrics, Maastricht, Netherlands; ${ }^{2}$ Rivierenland Ziekenhuis, Obstetrics and Gynaecology, Tiel, Netherlands; ${ }^{3}$ Isala Clinics, Obstetrics and Gynaecology, Zwolle, Netherlands

\subsection{6/ijgc-2021-IGCS.308}

Objectives Imiquimod could be offered as a non-surgical treatment alternative to LLETZ in treatment of high-grade CIN, for women who wish to avoid surgery. Short term effectiveness of imiquimod is $60-70 \%$. In the current study, we present the two-year follow-up results after successful initial imiquimod treatment, compared to LLETZ treatment.

Methods We performed a multi-center, non-randomized trial, in which women with a histological diagnosis of CIN 2/3 were treated with either imiquimod during 16 weeks or

Abstract EPV237/\#541 Table 1 Two-year treatment effectiveness

\begin{tabular}{|c|c|c|c|}
\hline & $\begin{array}{l}\text { Imiquimod } N=27 \\
N(\%)\end{array}$ & $\begin{array}{l}\text { LLETZ N=57 } \\
N(\%)\end{array}$ & $p$-value \\
\hline $\begin{array}{l}\text { Successful treatment } \\
\text { at two year follow-up }\end{array}$ & 25 (93) & $56(98)$ & \multirow[t]{2}{*}{$P=0.26$} \\
\hline $\begin{array}{l}\text { LLETZ treatment } \\
\text { during two year } \\
\text { follow-up }\end{array}$ & $2(7)$ & $1(2)$ & \\
\hline CIN diagnosis & & & $P=0.33$ \\
\hline$-\quad C I N 2$ & $2(100)$ & 0 & \\
\hline - $\operatorname{CIN} 3$ & 0 & $1(100)$ & \\
\hline $\begin{array}{l}\text { HPV positive at two } \\
\text { year follow-up }\end{array}$ & $6 / 19$ (32) & $13 / 41(32)$ & $\mathrm{P}=0.99$ \\
\hline
\end{tabular}

